\title{
TELEMEDICINE: THE NEXT GENERATION OF HEALTHCARE? ${ }^{1}$
}

\begin{abstract}
Telehealth is increasingly viewed as a cost-effective method to deliver patient care and expand access. --American Hospital Association
\end{abstract}

Telemedicine technology had advanced rapidly with the growth of the internet in the 2000's. The technology, also known as telehealth, allowed patients to receive medical care remotely rather than traditional in-person doctor visits at a facility. Consumer demand exploded throughout the 2010's, and some of the best hospitals in the world started implementing some forms of telehealth technology; some were subtle, some overt. However, for many hospitals like Lakeland Regional Health (LRH), telehealth was yet to be offered as a wide-scale option for patients to use.

Elizabeth, LRH's Chief Information Officer (CIO), had just come from a committee meeting where she and other executives discussed how telemedicine could be best implemented at LRH, if at all. The technology had only just begun to be technologically reliable, and the price tag for offering such services was heavy. Their immediate objective was to properly align LRH's entry into telemedicine services without sacrificing their high commitment to quality patient care. As Elizabeth began to unwind from work, she pondered questions regarding costs, government regulations, and how the telehealth adoption would affect LRH's financial position. After jotting down a few notes, she suddenly received a call; it was her sister Cindy.

Cindy explained that she was concerned about her daughter because she had displayed flu-like symptoms throughout the day and, unfortunately, she was not able to take her daughter to the emergency room (ER). Cindy remembered Elizabeth talking about telehealth, and how some of the local hospitals were offering telemedicine prescription services over the internet or phone app as an option instead of having to go to the ER for some medicine. Elizabeth referred her to the hospital offering the telemedicine services, but she wanted to be able to refer Cindy directly to LRH considering they were known for providing outstanding patient care.

Elizabeth wished Cindy's daughter well, and they said their goodbyes. Elizabeth knew that telemedicine could have been helpful for her sister that night. Now, even more, she was motivated to advocate for the project. She reflected on how LRH could offer telehealth services without compromising the quality of patient care and without negatively impacting the hospital's financial standing. Was this even possible?

\footnotetext{
${ }^{1}$ Copyright (C) 2018, Muma Case Review. This case was prepared for the purpose of class discussion, and not to illustrate the effective or ineffective handling of an administrative situation. Names and some information have been disguised. This case is published under a Creative Commons BY-NC license. Permission is granted to copy and distribute this case for non-commercial purposes, in both printed and electronic formats.
} 


\section{U.S. Healthcare Industry}

Recent years saw significant consolidation in the U.S. healthcare industry as many hospitals found they were not able to remain profitable without mergers and acquisitions. The industry had traditionally been very fragmented, lacking the centralization needed to adopt new processes and technologies effectively. Hospitals were a primary provider of healthcare in the United States in a \$1 trillion U.S. hospital industry (see Exhibit 1) (Curran, 2017). Barriers to entry were extremely high, as hospitals needed to hire large numbers of specialized staff to meet the wide variety of patient needs they encountered.

High labor costs and difficulty finding qualified personnel caused shortages of doctors and nurses across the industry. Attracting high-quality, talented hospital staff would be difficult for a new company without the type of established reputation of LRH. Outpatient treatment accounted for roughly half of the \$1 trillion in annual revenue generated by hospitals in the U.S. (see Exhibit 2). The need for flexible treatment models and access to doctors drove demand for the development of more efficient ways of minimizing outpatient wait times; telehealth appeared to have promising tools of doing so.

\section{Telemedicine Industry}

According to the American Telemedicine Association (ATA), Telemedicine was defined as: "The remote delivery of health care services and clinical information using telecommunications technology" (ATA, n.d.). In other words, it allowed patients to have remote access to doctors and nurses via telephone, online, tablets, and smartphone apps. Several types of non-emergency medical appointments could be done in the comfort of a patient's home such as:

- $\quad$ Post-care follow ups

- Specialty care

- Mental health treatment

- Prescriptions and refills

Elizabeth and her team had been hearing great things about telehealth and were in the process of analyzing the technology's potential at LRH. In the U.S. alone, the telehealth industry was valued at an astonishing \$572 million in 2014 (Grand View Research, 2016). Key drivers for the adoption of the new technology had been the demand for a centralized healthcare system, as well as enhanced quality and safety for patients via increased automation. Not only did the industry grow significantly quickly, but it was also projected to nearly triple over the next five years (see Exhibit 3).

Telemedicine had relatively recent innovations in the healthcare industry with advances in powerful wireless communication technologies like smartphones and tablets. Telehealth allowed doctor appointments to be made any place, any day, any time. Many telehealth interfaces allowed for a more sophisticated transmission of video teleconferencing with advanced biometric devices seamlessly providing patient vitals (see Exhibit 4). Any new telehealth service needed to be fully addressed regarding respect for patient privacy, customer satisfaction, diagnostic accuracy, and cost efficiency.

\section{A Brief History}

The innovation of telehealth medical care to patients over long distances had been around for ages. When communication between towns started to emerge in early Greece and Rome around 500 B.C., messengers could be used to communicate a doctor's advice or medicine from a long distance away (mdPortal, 2015). Births, deaths, and plague outbreaks were communicated via horns, fires, and smoke signals over long distances as civilizations advanced out into the world. 
The United States began pushing the telemedicine frontier further in the late 1950's when medical data like videos and images were first beginning to be transmitted electronically. Then, the National Aeronautics and Space Administration (NASA) further pioneered the technology to support astronaut's health in space. Neil Armstrong and his crew were equipped with medical telemetry and cardiac monitoring devices when he first stepped foot on the moon, July 21st in 1969. After that successful mission, the U.S. government began to invest more heavily in the technology to provide medical care for:

- Remote scientific stations in the Arctic and Antarctic

- Correctional facilities

- American Indian reservations

- War zones

The evolution of telemedicine grew rapidly in the 2010's with the advances of smartphone and tablet technologies. More than half of hospitals in the U.S. were using some form of telemedicine, with over 200 telemedicine networks operating and over 3,500 telemedicine service websites being used (Darves, 2013). Studies found that these services could improve care and reduce costs for patients, triggering consumer demand for LRH to provide telemedicine services. The technology was becoming less of a specialty offering and more of a mainstream service. Many reports indicated that the telehealth service industry was in a high growth pattern, and it was expected to continue growing.

\section{The State of Telemedicine Research}

One of the biggest problems Elizabeth and her team had with determining telehealth feasibility at LRH was that not much research accurately measured diagnostic accuracy, cost, patient satisfaction, and customer service. Many insurance payers would only provide reimbursement for telemedicine services if there was enough evidence that showed it could be used effectively and at a lower cost than current treatment options. Although there was some research suggesting cost-saving benefits of telemedicine, there were minimal studies that referenced clinical outcomes in healthcare (Coughlan, Eatock, \& Eldabi, 2006).

\section{Types of Services}

Patients with orthopedic injuries provided a good example of patients that needed to check in with their doctors, but would greatly benefit from telemedicine services. Someone with a severe orthopedic injury would likely have limited mobility, and their conditions would not change greatly from visit to visit due to the nature of orthopedics. Some orthopedic treatments were difficult for many patients to attend due to pain or transportation issues, especially considering the amount of follow-up appointments required.

The ability to speak to a doctor within minutes, any time of day or night was a powerful benefit of telehealth services. Non-emergency health concerns could be addressed by a remote health professional to discuss home-remedies, or prescribe medicine if needed. That was the model being used by Tampa General Hospital, one of the nearby hospitals to LRH. Tampa General Hospital had already started providing audio-visual telemedicine visits to patients through their website. These telemedicine visits had been especially useful for parents with young children deciding if they should seek further care.

Elizabeth also read an article describing how some evidence suggested that using telemedicine in school, to allow school nurses to communicate with parents and physicians, could prevent hospital visits and missed classes. The effective use of telehealth services in schools illustrated the various purposes and 
capabilities of telemedicine, as the school nurse and the patient/child had to speak with a physician, a pharmacist, and the child's parents to successfully administer care. Telehealth was a new platform that could accelerate many medical processes (“Telehealth Programs,” n.d.).

\section{Benefits to Patients}

The ability to provide health services remotely had been particularly helpful for those that lived in rural areas and needed care. The traveling distance for some patients to a hospital could be hours. It was also difficult to get enough specialized doctors working in remote areas, far away from concentrated cities. Since LRH served many of the less-populated and underserved communities between Tampa and Orlando, Elizabeth knew telemedicine had potential to revolutionize care for some of the hospital's patients. Benefits also included:

- Patients traveling from abroad that may not speak the native language could receive care.

- $\quad$ Nursing home patients would have immediate access to health professionals 24/7.

- Homebound patients could now use monitoring devices at home to transmit data like heart rate, blood pressure, and glucose levels to their doctors.

- Emergency room patients could have vital information transferred to doctors before even arriving at the hospital.

- Saving money. A telehealth visit typically cost about $\$ 49$--versus $\$ 95$ for an in-office or retail visit, $\$ 140$ or more for an urgent care clinic, and over $\$ 750$ for a trip to the emergency room.

\section{Lakeland Regional Health (LRH)}

LRH was a not-for-profit hospital, and the catalyst for community health that had served Lakeland and surrounding communities for the previous 100 years, going back to their origin as Morell Memorial Hospital. LRH's mission was to "deliver the best outcomes and safest care by placing people at the heart of all we do" and "improve lives every day by promoting wellness, education, and discovery" (“Hospital,” n.d.).

LRH had always been very committed to providing quality patient care and serving as more than just a hospital. LRH cared for the health and wellness of the Lakeland community. LRH was world-renowned for their superior emergency care (AHA, 2016). The hospital was one of few stand-alone, non-profit, fullservice/multi-specialty hospitals left in the country. Quality patient care was their priority, and the LRH team had been dedicated to using innovative health information technology to deliver the best patient outcomes.

"We have a passion for technological excellence at Lakeland Regional Health." --Elizabeth Kerns

At the time of the case, Lakeland was a city of 100,710 in Polk County, Florida, between Tampa and Orlando. The broader Lakeland-Winter Haven Metropolitan Statistical Area (a.k.a. Polk County) counted an estimated population of 623,009, according to the U.S. Census Bureau's July 2013 estimate. LRH focused on caring for these patients in their region, going beyond top-quality emergency care and other hospital services. LRH's goal was to improve the overall health and wellness of their community (Rufty, 2014). 


\section{Lakeland Regional Health's Market}

The population of Polk County was both growing and aging, which meant that demand for healthcare would continue to increase. Elderly residents utilized more health care services due to the greater incidence of health problems. About $17 \%$ of Polk County residents were 65 or older in 2013. The many children born during the post-WW2 "Baby Boom" were over 60 years old and, with medical advancements and safety improvements, these Americans were living longer than the generations before them. More-so, many older veterans had moved to Lakeland and Polk County areas in recent years. LRH's primary market was largely made up of Medicaid and Medicare recipients in the rural areas of central Florida. Elizabeth wondered if telehealth methods would be appropriate for LRH's market in Polk County (IBISWorld, 2016b).

Citizens of Polk County knew that they did not need to travel far for care because they were confident in the full range of high-quality medical services provided by LRH. The hospital had the benefit of serving their community for 100 years, generating a high degree of confidence in their talents from both patients and other healthcare providers. Relationships with primary care physicians and specialists throughout the community were essential because non-emergency hospital services often needed a referral from a medical practitioner first.

After establishing a century's worth of satisfied patient trust, LRH had a distinct advantage over lessestablished healthcare providers. It's location in the city of Lakeland provided a competitive advantage because of the hospital's commitment to quality patient care in that community. However, the rise of telemedicine technologies removed the need for the locality, and Elizabeth realized that LRH may have begun to miss out on market share to competing local hospitals already offering remote health services.

\section{Lakeland Regional Health Competitors}

Lakeland Regional Health's main competitors were freestanding Ambulatory Surgery Centers (ASCs), limited-service, freestanding, and specialty hospitals. Tampa General and Baycare were two such hospitals. Specialized healthcare facilities, typically owned by physicians that focused on a single area of care were growing quickly. ASC's did not treat severe cases or cases that required in-patient, follow-up treatment, which could lead to an increase in the severity of cases taken to hospitals. An increase in the average severity of the cases LRH treated could negatively impact profits (Curran, 2017).

LRH could expect competition for orthopedic patients from facilities like Florida Orthopaedic Institute. Evidence suggested that general hospitals had been improving their service offerings in direct competition with services offered by ASC's. Furthermore, the presence of ASC's was typically associated with the growth of high-tech diagnostic technology by general hospitals for the markets in which they competed with the ASC's. Technological innovation in telemedicine would be a smart area for LRH to plan to compete with ASC’s (Carey, Burgess, \& Young, 2009).

\section{Insurance Reimbursements}

Government agencies were LRH's largest payer through Medicare and Medicaid reimbursements for care, and regulations were considered strict. The Affordable Care Act had largely shaped the healthcare industry since it was passed in 2010. As telemedicine became more widespread, state legislatures and the federal government became more interested in regulating telehealth services. There was a need to address real and potential reimbursement and taxation issues. Much controversy surrounded the topic of health insurance coverage for telehealth because many insurance plans specifically did not pay for the services. 
Reimbursements from government-subsidized insurance through Medicare and Medicaid made up a larger portion ( $60 \%)$ of LRH's revenue than reimbursements from private insurance providers ( 25\%). For the rest of the industry, private insurance providers often made up a larger portion of the healthcare market than the government (see Exhibit 5). However, reimbursements from government health insurance were typically much lower than established hospital prices (Curran, 2017).

As recently as one year prior to the time of the case, the general opinion among healthcare professionals was that Medicare and Medicaid would not cover telemedicine services. Federal funding for Medicare and Medicaid had been and would continue to vary, as Medicaid funding was dependent on broader economic conditions in the United States (see Exhibit 6). If there was a way to save money without sacrificing effectiveness by using telemedicine, then the federal government would likely start allowing reimbursements for telehealth visits through Medicare and Medicaid.

\section{Software Vendors}

The technology required to provide quality telemedicine services was complex and expensive. Elizabeth knew that a clear path to a positive return on investment was critical for LRH's ability to adopt any new services. Not only would the hospital have needed to invest in more hardware and employees to get the new services launched, but deciding on a software platform provider was another difficult choice to be made. There were many vendors offering a platform-as-a-service (PaaS), all of which were promising seamless and reliable telemedicine software.

PaaS was a type of software solution that provided organizations with a basic computing infrastructure to build different web applications upon. It was a computing platform that would allow organizations like LRH to create apps without the complexity of buying and maintaining further infrastructure or software (Kepes, 2017). PaaS supported team collaboration for software development via web-based, user-friendly interfaces. In addition to creating, testing, deploying, hosting, and maintaining telemedicine applications, PaaS technology needed to handle patient billing management.

\section{Teladoc}

Operational since 2005, Teladoc had been one of the most popular telemedicine software vendors which received outstanding reviews from hospitals and patients across the nation. In 2013, the company reported 6 million members, and multiple independent experts validated the company's strong return on investment capabilities for hospitals and other health systems (AHA, 2016). Furthermore, the company provided marketing support to help client organizations increase the awareness and utilization of their services to patients.

Teladoc received multiple awards, including the 2016 North American Virtual Telemedicine Services Product Line Strategy Leadership Award and a 2016 Gold Pencil for Mobile Utility from The One Show. In 2017, The American Hospital Association awarded Teladoc with an exclusive endorsement for their ability to meet consumer demand for telehealth technology.

Teladoc had one of the fastest user-friendly interface systems on the market. After dialing in and selecting one of three broad options (general medicine, dermatology, or behavioral health), patients would be matched with a random doctor in less than two minutes on average (Tahir, 2015). Since telehealth companies competed on ease and speed of access to a doctor, this short wait time was a major competitive advantage over other telehealth services. Despite the speed, many patients disliked the matching of random doctors, and demanded greater control over selectivity. 


\section{American Well}

American Well (Amwell) was another distinguished telehealth service that provided SaaS software since 2006. Their smartphone apps were put together well and easy to use (see Exhibit 7). Just like other providers, Amwell would have provided LRH with the software infrastructure needed to support telemedicine services via apps, online, and tablets. The company had a good standing in the hospital industry. In fact, hospitals near LRH such as Tampa General, BayCare, and Nemours had already been successfully using Amwell services and would have been able to better advise LRH about their experiences with the software.

One thing Amwell seemed to have innovated better than others was telehealth kiosks. "With American Well's telehealth kiosks - the industry's only kiosks that offer walk-in, unscheduled visits - patients anywhere can get immediate access to a U.S. board-certified physician, dietitian, or behavioral health counselor (Pennic, 2015). It was projected that the market for healthcare kiosks would rise from 360\% from 2015-2020, and no other telemedicine software providers could develop them better.

Amwell did have longer wait times than some competitors, and queue time was an important factor in the investment decision. The average wait time for patients was eight minutes, about $400 \%$ the wait time of Teladoc. This longer average was mainly due to more doctor options available to patients upon dialing in. Unlike Teladoc's three broad options, patients could select specific doctors based on their specialty and experience. Patients could also see a picture and short biography of the physician they selected, allowing users to bookmark the same doctor for next time if they chose to do so.

\section{Custom Software}

Another software option LRH had for implementing new telehealth services was a tailor-made software system built from scratch, eliminating the need to decide which SaaS provider to invest in. The biggest benefit of this route would have been the ability to configure and design the software interface precisely to the needs of LRH in terms of data transfer, doctor matching, and pricing structures.

Elizabeth played a significant role in getting LRH to go paperless with Electronic Health Records (EHRs) around 2010. EHRs were the digitized forms of patient information. It included data on history, physical exams, investigations, treatments, and more about patients. This technological advancement had vast arrays of benefits over the paper documents used in the past like: decreased costs, improved quality of care, and better access to health care (Ozair, Jamshed, Sharma, \& Aggarwal, 2015). Immediate compatibility with LRH's current EHR software systems could have been established if the hospital built their own custom software system. In addition, LRH would have complete control over the inclusion or exclusion of which telehealth services to provide as time progressed.

One major drawback to the customized software approach would have been the need to hire consultants, software developers, and IT personnel. Purchasing an off-the-shelf software package through Teladoc or Amwell would likely have been cheaper to implement. Long-term maintenance and support were major concerns for Elizabeth with the tailor-made telehealth software path.

"In my 30-year career in IT leadership, the buy versus build decision usually ends in buy because long term support of a custom-build is difficult and expensive." --Elizabeth 


\section{Technical Problems with Telemedicine}

\section{Electronic Health Record (EHR) Transfer}

LRH had only just begun to get settled in with their new EHR systems a few years prior to the telehealth implementation idea, so the team was well aware of the complications and ethical issues that come with electronic data transfers. Data inaccuracy was only a minor concern compared to the security breaches that threatened patient privacy. The entire medical industry had yet to come to a consensus as to the best way to create, transfer, and store digital patient information in a way that was both safe for patients, and compliant with governmental regulations.

Despite their risks, Elizabeth knew robust EHR systems were required for any telemedicine service to work. Was LRH ready for yet another electronic obstacle course?

\section{Infrastructure}

One major problem with telemedicine had been the need for a broadband infrastructure strong enough to support the large bandwidth needs of a video-conference. Strong connections were a challenge for many of LRH's rural communities. Weak connections would lead to poor video streams that were blurry or glitchy, which was unacceptable when providing any critical service like medical care (Ripton \& Winkler, 2016).

Elizabeth knew that LRH had a high standard of quality for their patients. Considering many of LRH patients lived in rural areas, she began considering if telemedicine service was even an option. If key information or directions were to be misinterpreted by a patient due to bad reception, LRH would have to walk down the slippery slopes of potential liability.

\section{Impersonality}

Elizabeth thought about what the user experience would be like seeing a doctor through a phone app compared to in person. There was no physical examination in telemedicine. Without the face-to-face interaction that most people were used to, patients could feel a sense of detachment. According to Cecilie Bisgaard-Frantzen of the University of California Berkeley Wellness, "A good doctor-patient relationship is characterized by trust and intimacy. Patients often bring up issues during a doctor's visit that go beyond their immediate health problem” (Bisgaard-Frantzen, 2015).

If a patient did not feel a real sense of trust, many issues may have gone undiscussed. Even if an issue was brought up by the patient, some non-verbal cues may have slipped through the cracks. With telemedicine, patients needed to rely on their doctor's ability to communicate recommendations descriptively, as well as the physician's ability to listen to the patient for a proper diagnosis.

LRH was proud of the close relationship that they had established with the local community over the years, and Elizabeth knew the impersonality of a diagnosis over a telephone screen could have the potential to impact the level of exceptional patient care LRH had been known to provide.

\section{Challenges and Behaviors Driving Lakeland Regional Health (LRH)}

The ability for LRH Medical Center to continue operating smoothly had required constant attention to detail and innovation. Unlike other companies, medical centers had dealt with and would continue to deal with people and their health. Any changes, including the technological changes that LRH had implemented in the past, had required an incredible amount of effort to get everyone on board. Numerous 
details such as the timeline of implementation, budget, current legislation, and regulations had made process improvement difficult.

The struggle had been amplified by all the internal stakeholders involved, ranging from nurses and physicians to financial executives and staff accountants. The vast array of medical professionals employed at LRH made technological change difficult to implement. For example, what was preferable for the physicians may not have been preferable to the finance team. Multiple departments with differing needs, priorities, and responsibilities made targeting the overlap of interest key for the decision-making team at LRH.

\section{Wide-Ranging Professional Staff}

The sheer diversity of the staff at LRH made coming to a consensus a near-impossible task with new technologies. Getting the physicians, finance teams, and the executives all to agree on a course of action had proven to be a challenging task. Would the doctors have seen the same benefit to implementing telemedicine that an accountant with numerous charts depicting costs-savings saw? Alternatively, would the disparity between their jobs prevent them from coming to a consensus?

After all, the finance team may have looked at a decision from a cost perspective, and glossed over the fact that the doctors would be forced to amend the practices they had spent years perfecting. How could a person on the budget committee understand bedside manner behaviors, that now needed to be done in a separate physical location away from the patient? Any major decisions that the medical center leadership had faced have had to deal with reconciling the thoughts and wishes of multiple departments full of people with vastly different responsibilities. The medical center had tried to mitigate some of the potential disagreement by including physicians and nurses in their executive team to form a more collaborative decision-making process.

\section{Technology Change in Healthcare}

Elizabeth understood that IT changes in Healthcare would be a slow process when compared to other industries. Tough government regulations made change difficult. Moreover, doctors were often resistant to adopting new technology, as patient care was their priority focus. Support of IT infrastructure innovations tended to take a backseat in priority for a regular doctor or nurse.

Resistance to technological change in the healthcare industry greatly diminished after the Affordable Care Act was passed in 2010. Requiring the digitization of patient medical records caused the most stubborn doctors to leave the industry, and encouraged more advanced technological thinking among healthcare professionals.

According to Elizabeth, LRH had the busiest standalone emergency department in the country, serving 220,000 patients per year, $85 \%$ of whom were in and out in under three hours. LRH challenged the idea that emergency care should involve extensive waiting with their mastery of emergency care. The LRH emergency room was viewed by healthcare professionals from around the world looking to learn about emergency care. Innovation in telemedicine might have further separated LRH by increasing patient satisfaction, reducing cost, and maintaining effectiveness. 


\section{Governmental Regulation}

Governmental legislation and regulation had made the decision-making process complicated for Elizabeth and her team. Hospitals and medical centers all over Florida often had to fight for telehealth service reimbursement. Then in March of 2016, the Florida Legislature passed a bill setting the stage for telehealth commercial insurance coverage. Although the bill was not an insurance coverage mandate, it did put into place several provisions that allowed for greater telehealth service reimbursement ("State Telehealth Laws,” 2017) (see Exhibit 8). The hyper-regulation found in the healthcare industry created many obstacles for medical centers in Florida and across the United States.

To make things even more complex for widespread adoption of telemedicine, regulations for reimbursements varied across state lines. For example, Rhode Island had neither a Medicaid nor a Private Payer coverage and reimbursement policy for Telemedicine (see Exhibit 9).

"We must constantly be reviewing and be up-to-date with the latest legislation, to avoid any potential penalties or loss of money." -Elizabeth

Although there were many success stories of hospitals benefiting from telehealth use, the differing laws among states made most comparisons difficult. Elizabeth knew that she also had to compare how the laws and standard practices would align to those in Lakeland, Florida. Careful consideration of both federal and state law had significantly affected the LRH team's decision-making process and would likely continue to do so for some time.

\section{The Decision}

Upon completing her investigation of the various telemedicine software systems, Elizabeth knew that the time for LRH to make a decision had come. LRH's objective was to properly implement telemedicine technology while also maintaining their high standards of patient care. Elizabeth was faced with several decisions offering different advantages and disadvantages to each option. Her follow-up meeting was tomorrow, and the committee would be making a formal recommendation to the Board based on the research that was gathered. She wondered how the board would approach the decision to add telemedicine technology to their repertoire of services given the recent consumer demand for telemedicine services. The committee considered the following 4 options:

1. Do nothing. Telemedicine technology was costly, and only two other competing hospitals had implemented telemedicine programs. LRH should wait to see if the telemedicine program would be successful for their competitors, and continue to focus on their profitable strengths rather than proceeding forward with telemedicine technology for the time being.

2. Partial implementation of a reputable telemedicine software technology using a platform such as Teladoc or American Well. Implementation phases would be piloted to their employees first, and based on its success would then be implemented to their patient base.

3. Full implementation of either Teladoc or American Well telemedicine technology as an additional service offered by LRH to their patients and their employees to begin competing with other local hospitals in the area.

4. Create a customized telemedicine software platform to ensure a seamless integration of EHRs. 


\section{References}

American Hospital Association (AHA). (2016). Telehealth: Helping hospitals deliver cost-effective care. Retrieved May 01, 2017, from http://www.aha.org/content/16/16telehealthissuebrief.pdf

American Telemedicine Association (ATA). (n.d.). About telemedicine. Retrieved April 30, 2017, from http://www.americantelemed.org/main/about/telehealth-faqs-

Bisgaard-Frantzen, C. (2015). Is telemedicine right for you? Berkley Wellness. Retrieved from http://www.berkeleywellness.com/healthy-community/health-care-policy/article/telemedicineright-you

Carey, K., Burgess, J. F., \& Young, G. J. (2009). Single specialty hospitals and service competition. Inquiry: The Journal of Health Care Organization, Provision, and Financing, 46(2), 162-171. Retrieved from http://journals.sagepub.com/doi/abs/10.5034/inquiryjrnl_46.02.162

Coughlan, J., Eatock, J., \& Eldabi, T. (2006). Evaluating telemedicine: A focus on patient pathways. International Journal of Technology Assessment in Health Care, 22(1), 136-142. Retrieved from https://doi.org/10.1017/S0266462306050938

Curran, J. (2017, March). Hospitals in the US. IBISWorld Industry Report 62211. Retrieved from IBISWorld Database.

Darves, B. (2013). Telemedicine: Changing the landscape of rural physician practice. Retrieved from http://www.nejmcareercenter.org/article/telemedicine-changing-the-landscape-of-rural-physicianpractice/

Grand View Research. (2016). U.S. telehealth market analysis, by product. Retrieved from https://www.grandviewresearch.com/industry-analysis/us-telehealth-market

Kepes, B. (2017) Understanding the cloud computing stack. Retrieved from https://support.rackspace.com/white-paper/understanding-the-cloud-computing-stack-saas-paasiaas/

mdPortal (2015). History of telemedicine. Retrieved from http://mdportal.com/education/history-oftelemedicine/

Ozair, F., Jamshed, N., Sharma, A., \& Aggarwal, P. (2015). Ethical issues in electronic health records: A general overview. Retrieved from https://www.ncbi.nlm.nih.gov/pmc/articles/PMC4394583/

Pennic, J. (2015). 3 benefits of telehealth kiosks. Retrieved from http://hitconsultant.net/2015/08/27/3benefits-of-telehealth-kiosks/

Ripton, J., \& Winkler, S. (2016). How telemedicine is transforming treatment in rural communities. Retrieved from http://www.beckershospitalreview.com/healthcare-information-technology/howtelemedicine-is-transforming-treatment-in-rural-communities.html 
Rufty, B. (2014, June 26). Census shows Polk’s population growth tops state, nation. The Ledger. Retrieved April 22, 2017, from http://www.theledger.com/

State telehealth laws and reimbursement policies report. (n.d.). Retrieved April 21, 2017, from http://www.cchpca.org/state-telehealth-laws-and-reimbursement-policies-report/

Tahir, D. (2015). Telehealth services surging despite questions about value. Retrieved from http://www.modernhealthcare.com/article/20150221/MAGAZINE/302219981

Telehealth programs. (n.d.). Retrieved April 23, 2017, from https://www.hrsa.gov/ruralhealth/telehealth/ 


\section{Biographies}

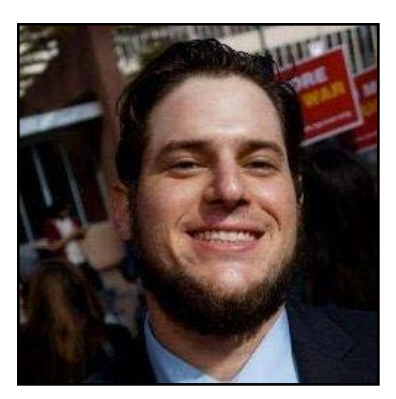

Evan Eisenberg graduated from USF's Honors College in 2015 and is currently an MBA student at USF's MUMA College of Business, a marketing professional, and advocate for medical cannabis research. He works with the Marketing Department at USF to improve USF's web presence. Eisenberg has collaborated with scientists at the University of South Florida to advance the state of medical cannabis research and highlight the cannabinoid research already being conducted at USF. Eisenberg has also organized and assisted with federal and state drug policy lobbying efforts, and has been active in reforming USF's drug policies, writing the USF System's Medical Amnesty Policy as part of a campaign to reduce overdose deaths.

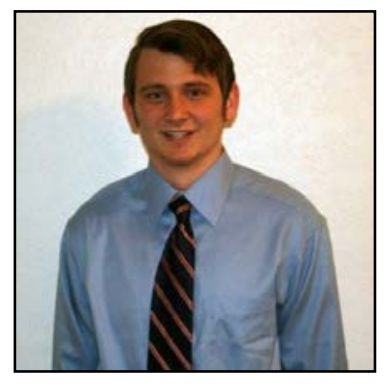

Ross Louk graduated from the University of Florida in 2014 with a degree in Political Science, Business Administration, and Russian Language. He is presently pursuing an MBA at the University of South Florida with an anticipated graduation date of Spring 2019. Ross has been in the accounting field for three years and currently works as an accountant for the global law firm DLA Piper.

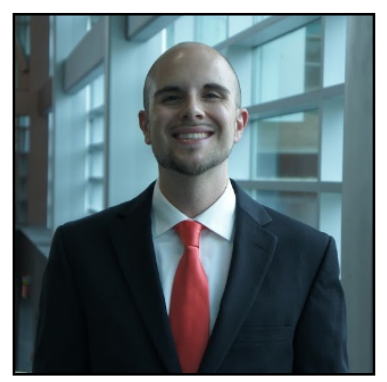

Sam Mohammad, co-founder and marketing director of Modern Business Consulting, has over eight years' experience managing marketing operations throughout several leadership roles in college, military, and business.

He managed supply operations for Heavy Marine Helicopter Squadron 302 for over four years and is certified through CSCMP as a supply chain operations management specialist. Sam holds a B.S. in Management with a specialization in Marketing from the University of Phoenix, Tampa. He is earning his MBA at USF, Tampa and expected to graduate Spring of 2018.

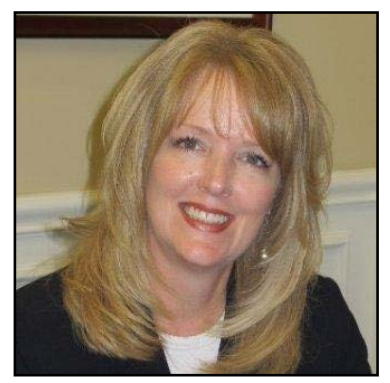

Deborah Vaughan graduated from the University of South Florida in 2014 with a Bachelor of Science degree in Business Management. She is currently pursuing her MBA at the University of South Florida with a Fall 2017 target for graduation. Deborah is Vice President for a local community bank in Sarasota, Florida and manages their flagship office as the Banking Center Manager. Deborah is also an active member of the Board of Directors for a local nonprofit organization called Josh Provides, an Epilepsy Assistance Foundation. 


\section{Exhibit 1: Key Statistics Snapshot for Hospitals in the U.S.}

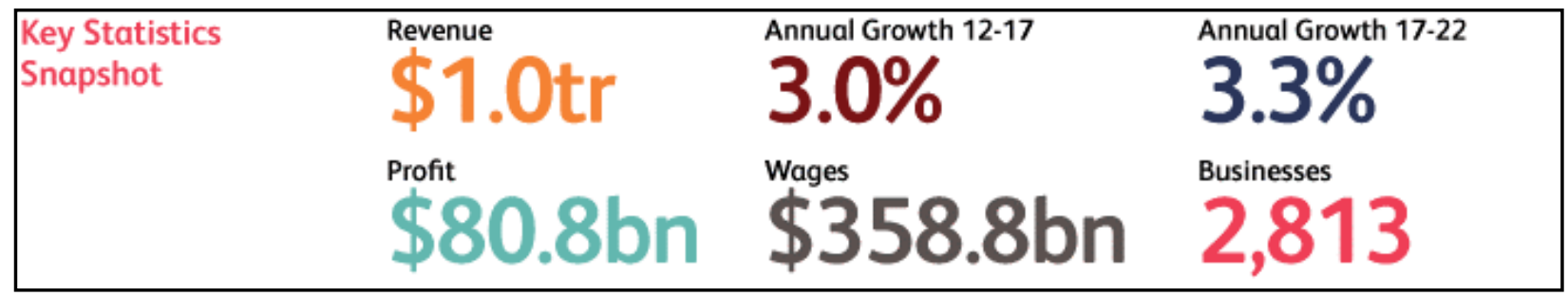

Source: Curran, J. (2017, March). Hospitals in the US. IBISWorld Industry Report 62211. Retrieved from IBISWorld Database. 


\section{Exhibit 2: U.S. Hospital Products and Services Segmentation (2017)}

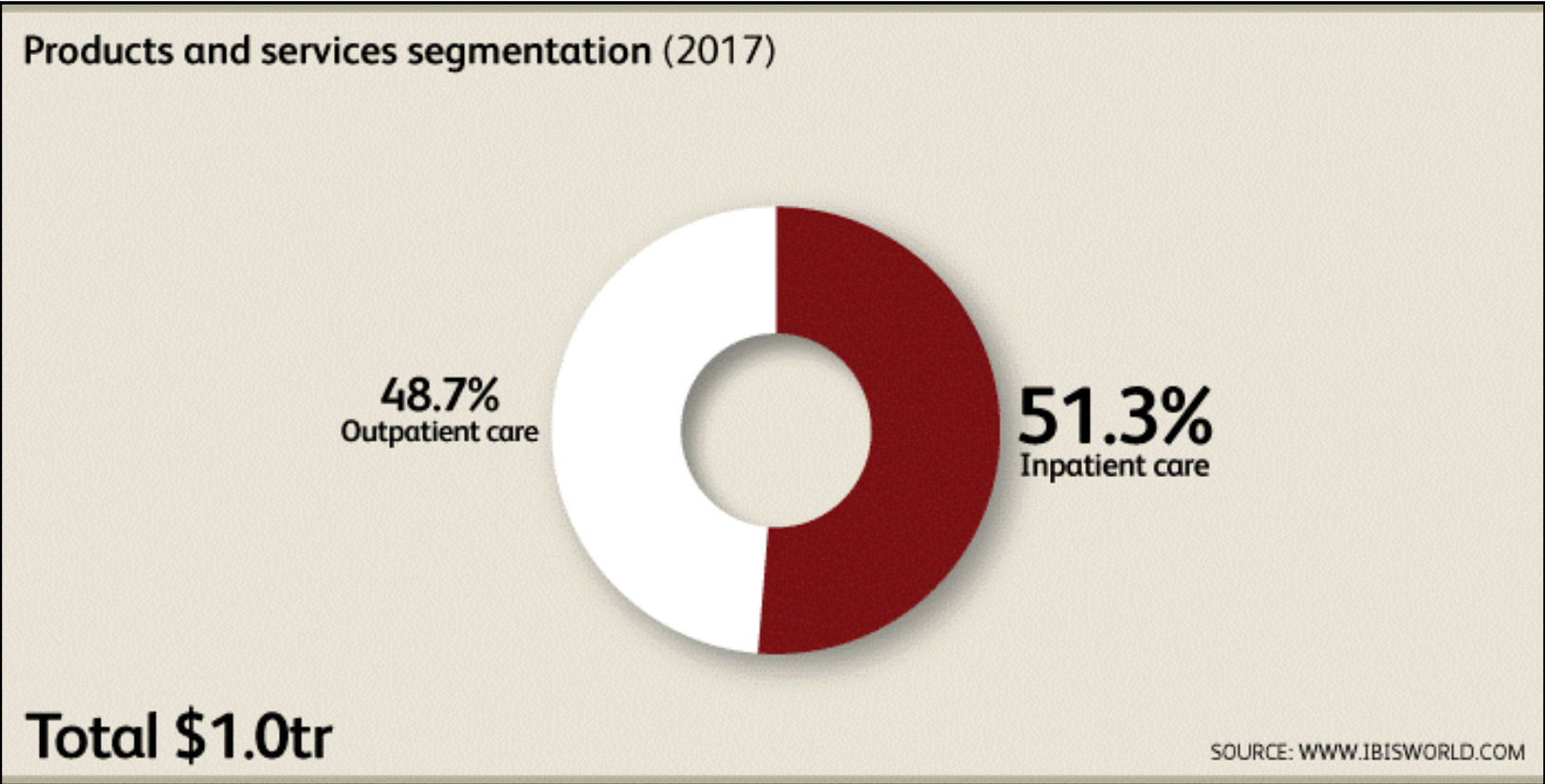

Source: Curran, J. (2017, March). Hospitals in the US. IBISWorld Industry Report 62211. Retrieved from IBISWorld Database. 
Exhibit 3: U.S. Telehealth Market Analysis, by Product.

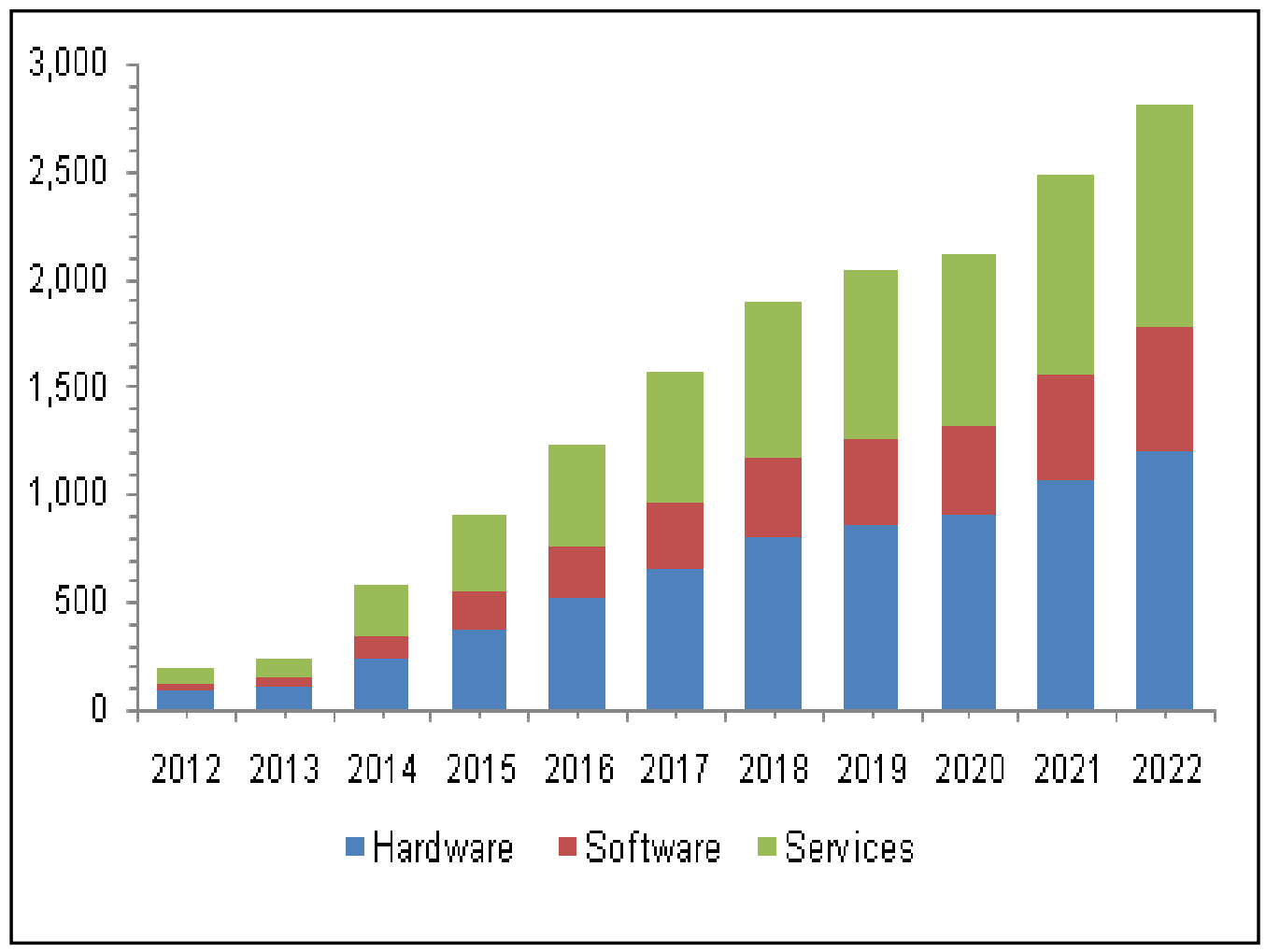

Source: Grand View Research. (2016). U.S. telehealth market analysis, by product. Retrieved from http://www.grandviewresearch.com/industry-analysis/us-telehealth-market 


\section{Exhibit 4: Telemedicine Kit Cart 1}

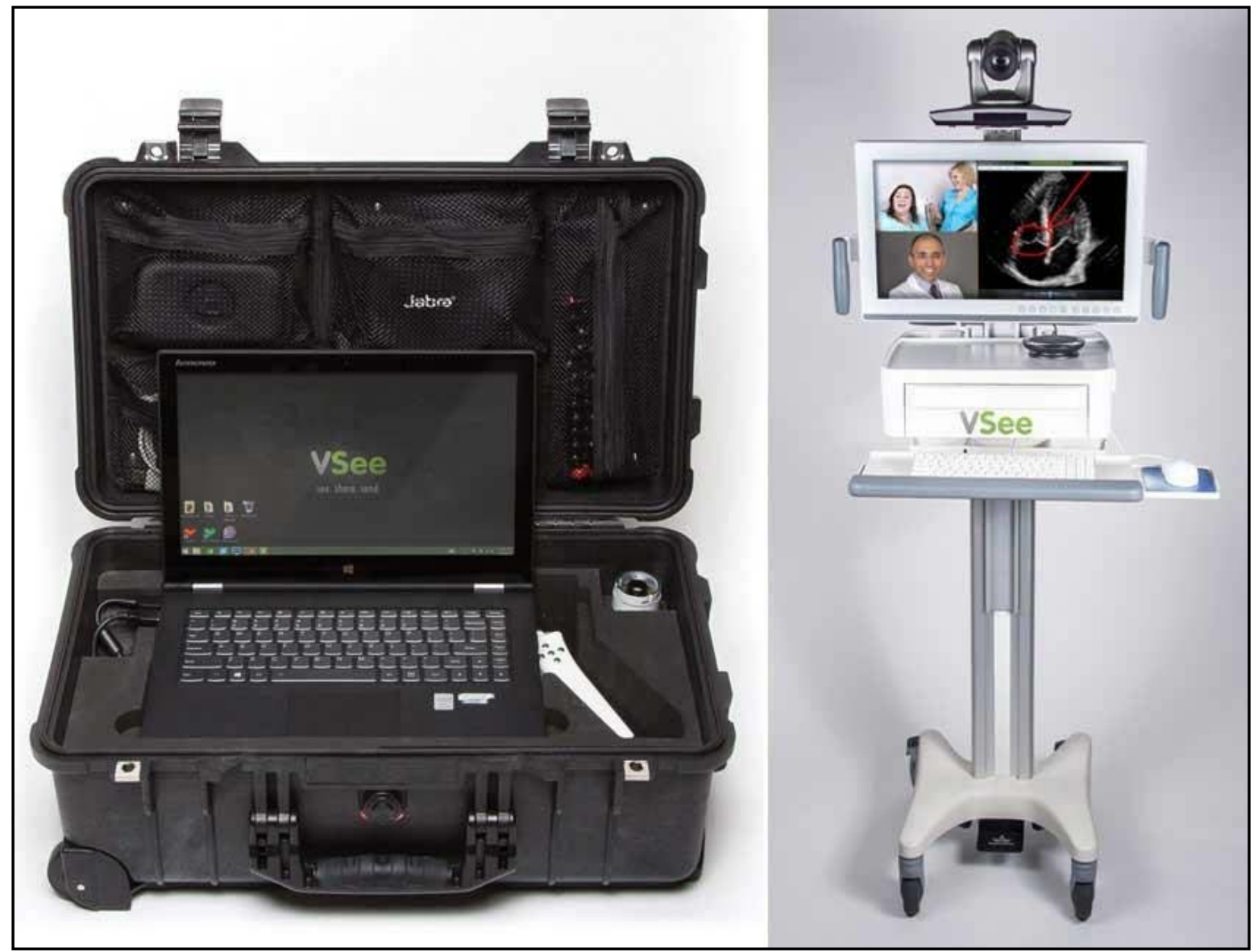

Source: Telemedicine Kit Cart 1 [Digital image]. (n.d.). Retrieved April 22, 2017, from https://vsee.com/wp-content/uploads/2015/03/telemedicinekitcart1.jpg 


\section{Exhibit 5: U.S. Hospitals Major Market Segmentation (2017)}

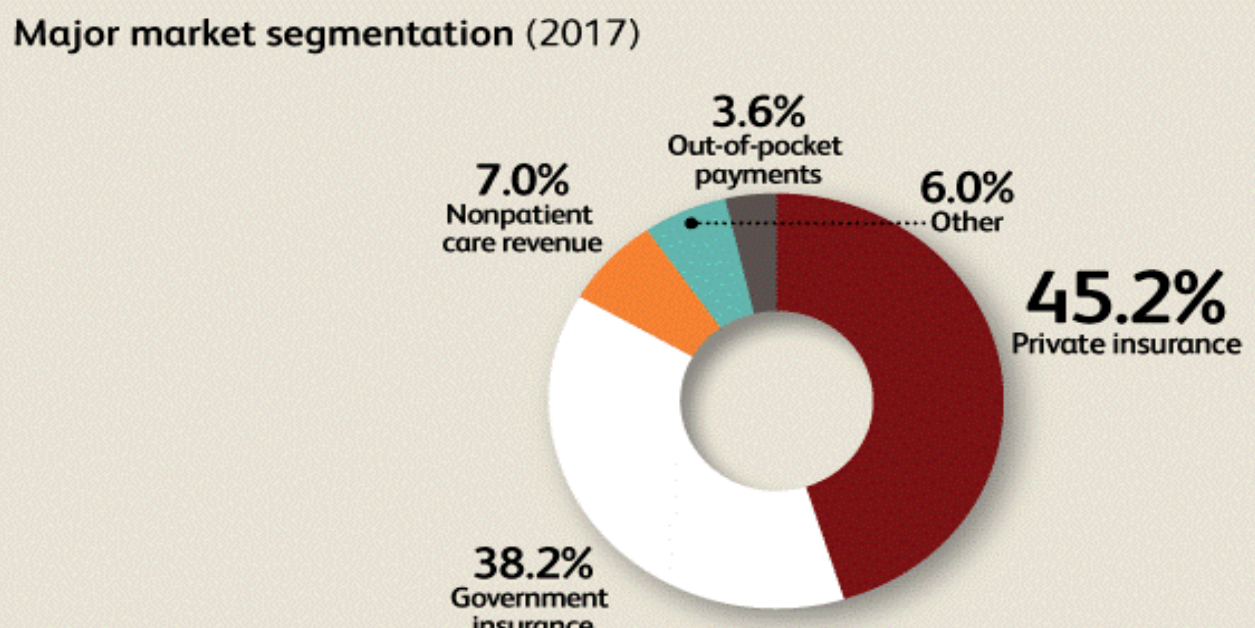

Total \$1.0tr SOURCE: WWW.IBISWORLD.COM

Source: Curran, J. (2017, March). Hospitals in the US. IBISWorld Industry Report 62211. Retrieved from IBISWorld Database. 


\section{Exhibit 6: Federal Funding for Medicare and Medicaid}

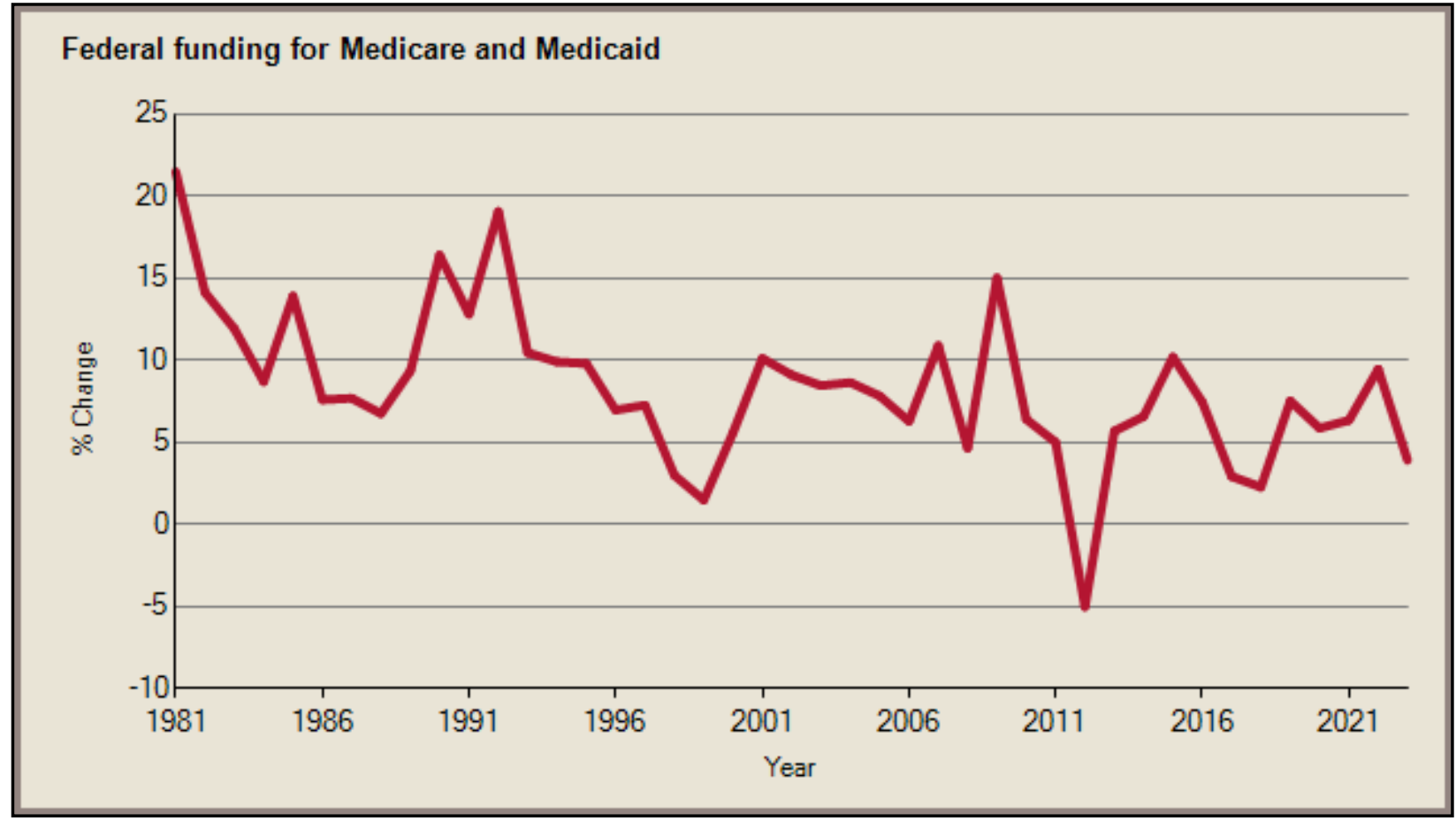

Source: IBISWorld. (2016, July). Federal funding for Medicare and Medicaid. IBISWorld Business Environment Report. Retrieved from IBISWorld Database. 


\section{What is Telehealth?}

Telehealth, sometimes called telemedicine, is a remote consultation between a doctor and a patient. We believe - as does the Federation of State Medical Boards - that for telehealth to be a true healthcare encounter, several tenets must be upheld: immediacy, patient choice, video and care continuity. In contrast, some telehealth providers offer "healthcare roulette," telephone call-back services whereby a patient is paired with an anonymous doctor, most frequently for a telephone call at a later time.

Figure 1: How A Telehealth Visit Works

1.

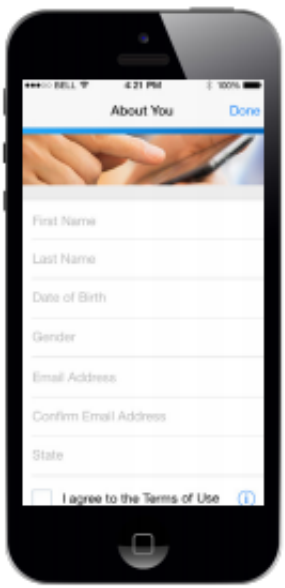

Enroll

\section{2.}

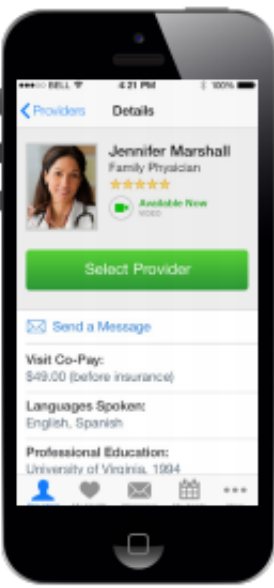

Select a provider

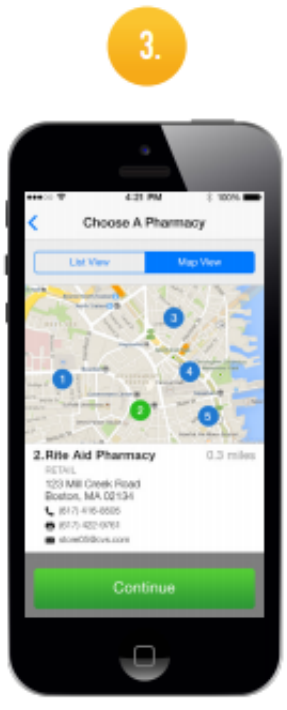

Choose a pharmacy
4.

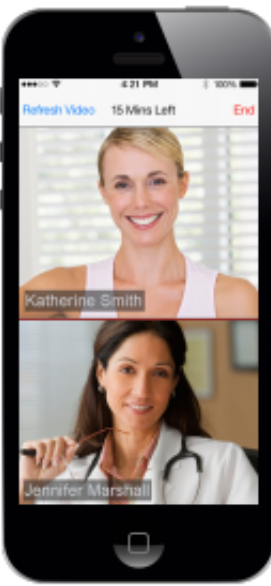

See the doctor
5.

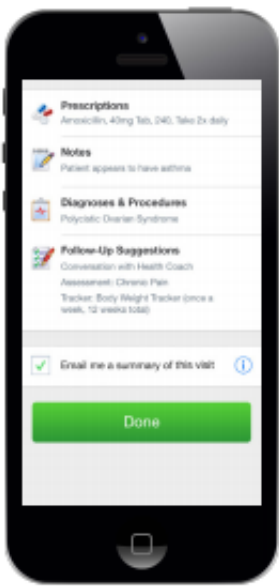

Get a visit summary

Source: http://go.americanwell.com/rs/335-QLG-882/images/Employer-Best-Practices-eBook.pdf 
Exhibit 8: Twenty States Allow Physician-Patient Relationships to Be Established via Telehealth Technologies

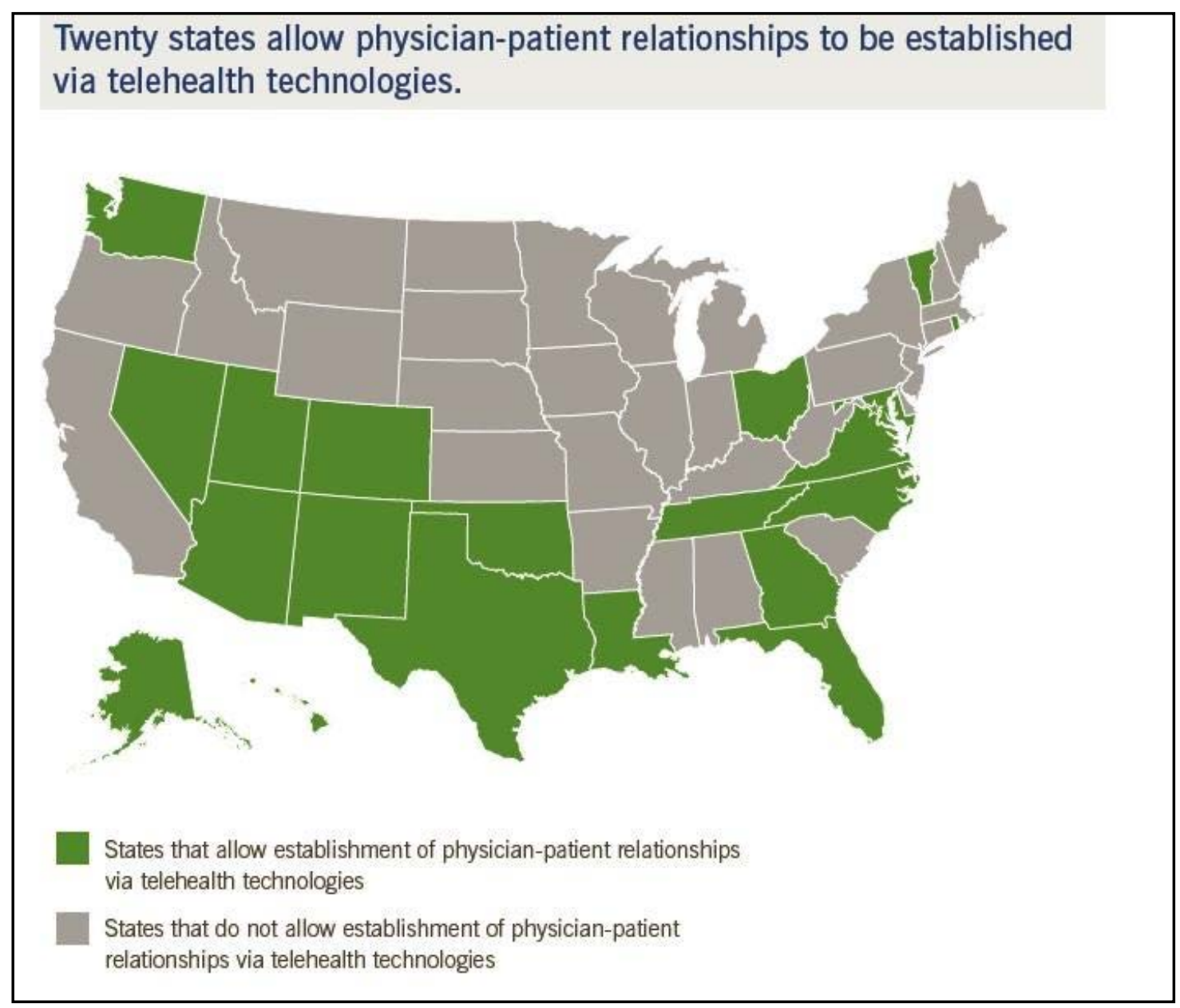

Source: http://www.ahca.myflorida.com/SCHS/telehealth/docs/3 21_17TAC MeetingMaterials.pdf 